\title{
Narrativas policiais, crenças jurídicas e a construção da verdade sobre o crime de tráfico de drogas
}

\author{
Eduardo Casteluci'
}

Resenha do livro:

JESUS, Maria Gorete Marques de. A verdade jurídica nos processos de tráfico de drogas.

Belo Horizonte, Editora D’Plácido, 2018.

Editado com base em sua tese de doutoramento, o livro de Maria Gorete de Jesus identifica que, nos casos de tráfico de drogas, as narrativas criadas pelos policiais militares em seus autos de prisão em flagrante possuem papel determinante no processo de produção da verdade jurídica. Mais precisamente, a pesquisadora relata a cadeia de transposições das narrativas policiais aos autos dos inquéritos policiais e, em seguida, dos processos penais, em cujo desenrolar seu regime de verdade é incorporado e validado pelos operadores do sistema de justiça criminal. Na antessala desse regime de funcionamento do sistema de justiça criminal está - conclui a pesquisadora - um sistema de crenças compartilhado por todos os seus operadores cuja razão fundante é uma determinada compreensão sobre a função punitiva da justiça criminal, bem como um determinado entendimento sobre os critérios que medem a sua eficácia.

Em sua tese, portanto, a autora congrega pelo menos três segmentos distintos desse campo. O primeiro diz respeito às análises do combate ao tráfico de

1 Programa de Pós-Graduação em Sociologia da Universidade de São Paulo (PPGS/USP) - São Paulo Brasil - eduardo.casteluci@gmail.com 
drogas no Brasil, bem como da seletividade estatal em relação a quais setores e territórios da economia da droga exercer com maior vigor sua capacidade repressiva (cf. Rui, 2012). O segundo, aos estudos sobre as formas de policiamento, à segurança pública e às práticas policiais em geral, segmento em que se consagrou o estudo da discricionariedade e da arbitrariedade dos policiais militares brasileiros na consumação de seus mandatos legais (cf. Teixeira, 2012). Finalmente, o terceiro se refere às investigações sobre os regimes de verdade e sobre o processo de construção da verdade jurídica no sistema de justiça criminal (cf. Foucault, 2005), bloco fundamentalmente marcado pelo exame dos inquéritos policiais e da forma como são recebidos e incorporados no processo penal (cf. Lima 1989; 1994; Misse, 2010).

A contribuição específica deste livro é justamente identificar, e se propor a preencher, uma importante lacuna que é produzida na intersecção entre esses ramos de pesquisa. Isto é, de que maneira a comprovada centralidade do policiamento ostensivo na definição sobre como a política estatal de combate ao tráfico de drogas é efetivamente implementada nas avenidas e vielas das cidades brasileiras se combina com o tipo de resposta oferecida pelo sistema de justiça criminal, e seus operadores, à demanda punitiva que lhe é resultado.

Em suas escolhas metodológicas (ver o capítulo 2), a pesquisadora novamente busca combinar os principais recursos empíricos dessas perspectivas. Empreende, em primeiro lugar, a análise da legislação que regulamenta o combate ao tráfico de drogas no Brasil, de modo a distinguir a natureza formal de suas implicações práticas. Conduz, em seguida, o exame do fluxo no sistema de justiça criminal de um grupo de casos de tráfico de drogas ocorridos na cidade de São Paulo, o que a permite descrever precisamente que tipo de filtros e critérios são aplicados pelos operadores do direito e quais, entre eles, são os mais importantes para a predição de um desfecho processual condenatório. Assim, complementa essa operação com a pesquisa etnográfica dos autos das prisões em flagrante, dos inquéritos policiais e dos autos processuais estrito senso. Com isso, consegue acessar indícios de processos sociais mais gerais transcritos nos documentos oficiais e, posteriormente, cotejá-los com as falas dos próprios operadores do direito que entrevistou. Finalmente, ainda observa diretamente as audiências de custódia, instrução e julgamento de um conjunto de casos, captando as dinâmicas da interação entre os agentes do Estado e os réus e seus defensores.

Passemos, agora, ao exame mais detido dos argumentos. A Lei n. 11.343/2006, que cria Sistema Nacional de Políticas Públicas sobre Drogas, estabelece tratamentos distintos a "usuários" e "traficantes de drogas", conformando um 
dispositivo médico e criminal, respectivamente. Entretanto, a norma deixa de definir critérios objetivos para que os agentes do Estado operem os mecanismos de distinção. Mais propriamente, atribui a eles a prerrogativa de avaliar as circunstâncias de cada caso e de cada suspeito de modo a discernir uma conduta da outra (Jesus, 2018: 46). Uma mesma quantidade de drogas apreendida pode ser considerada como possivelmente destinada ao consumo ou ao tráfico, dependendo, por exemplo, do local em que foi apreendida e das características pessoais e socioeconômicas de seu portador, bem como do tipo de atitude que exibiu diante da abordagem policial. Nesse momento, não existem impedimentos formais à utilização de categorias vinculadas a marcadores sociais discriminatórios, tal como a associação entre raça, pobreza, território e criminalidade. Na prática, os critérios mobilizados pelos policiais são aqueles cujo sentido é determinado com base em um "saber" - um modo de ver e interpretar o mundo - que compartilham entre si (cf. Muniz, 2012).

No momento da transcrição do mundo social lido por meio do "saber" policial ao mundo dos autos das prisões em flagrante, os policiais militares, então, passam a mobilizar um tipo de "vocabulário de motivos" (cf. Mills, 1940) cuja principal capacidade é sublimar suas condutas e motivações extralegais em categorias judicialmente conhecidas e, sobretudo, aceitáveis. Na narrativa dos acusados, por exemplo, são frequentes as denúncias de algum tipo de tortura policial como forma de obter uma confissão sobre a intenção de venda das drogas. Ainda que o acusado acabe por confirmar a presunção policial, o método utilizado é absolutamente incompatível com os regulamentos da atividade policial. Contudo, nos autos essa ação é simplesmente registrada como uma "confissão informal", e é por meio desse termo que o "indício" de autoria do crime será conhecido, em primeiro lugar, pelo delegado de polícia (Jesus, 2018: 110).

Quando a polícia militar apresenta um acusado, preso em flagrante por suspeita de tráfico de drogas, ao delegado de polícia, este instaura o inquérito policial, em que devem ser conduzidos os procedimentos investigativos para a verificação da possível conduta criminosa. No entanto, o produto final do trabalho do delegado consiste, nesses casos, apenas na reprodução - ajustada à forma do inquérito - da "verdade dos fatos" conforme havia sido narrada pelos policiais militares. Em outros termos, o que é produzido por meio do "saber" policial é assumido enquanto "verdade" pelos delegados. Esse é o primeiro estágio daquilo que a pesquisadora chama de regime de validação das narrativas policiais (Jesus, 2018: 117). Já o segundo se inicia nas audiências de custódia, em que entram em cena os demais membros do sistema, isto é, promotores e juízes, além dos defensores. 
O contato dos promotores com o caso ocorre por meio do inquérito policial, que é, em geral, apenas reproduzido agora na forma de uma denúncia criminal. O juiz, por sua vez, deve necessariamente ponderar, na sua decisão sobre a manutenção da prisão, também as informações prestadas pelo acusado e por seu defensor. Nesse momento, ocorre o embate entre a "verdade dos fatos" produzida pelos policiais e a narrada pelo acusado. E, com isso, passa a ser notável um repertório de crenças compartilhado pelos operadores do direito. Por um lado, creem na retidão do trabalho policial e na necessidade de sua função para a manutenção da ordem pública - este que é o objetivo primordial da justiça criminal. Por outro, creem que o acusado fará o que puder para evadir da justa punição, isto é, pressupõe-se que ele convenientemente mentirá. No confronto entre fatos, o "saber" policial é novamente validado.

Outra expressão presente nas manifestações de promotores e decisões de juízes para justificar a adesão às narrativas policiais consiste na "presunção de veracidade", a qual atribuem aos agentes policiais. Este enunciado equivale ao sentido da "fé", ambos ligados ao "universo da crença" [...] Ao serem utilizadas como expressões que justificam a recepção das narrativas policiais, os operadores do direito dispensam a necessidade de conhecer, de compreender a fundo, de questionar os casos (Jesus, 2018: 198).

Juízes e promotores perguntam aos acusados: se é verdade que o policial te torturou, se é verdade que ele tentou lhe extorquir, por qual razão teria feito isso? Não se admite que as más condutas policiais - fartamente documentadas - sejam atributos da organização, e sim de maus policiais cujas motivações pela ilegalidade devem, de algum modo, ser conhecidas pelas suas vítimas para se tornarem críveis (Jesus, 2018: 152). As narrativas policiais são relativizadas, relata a pesquisadora, apenas quando se verifica a proximidade social do acusado em relação aos operadores do direito. Nesses casos, a quantidade de drogas, por exemplo, pode ser considerada insuficiente para denotar a possibilidade de venda, bem como concluir-se que o acusado não representa, de fato, uma ameaça à ordem pública, recebendo o direito de responder ao processo em liberdade (Jesus, 2018: 173).

Esse regime de verdade segue em plena eficácia nos momentos posteriores do processo, ou seja, nas audiências de instrução e julgamento (ver capítulo 6). Neles, o trabalho dos promotores serve para transformar os "indícios” levantados pela polícia em provas judicialmente válidas, já que são reproduzidas em juízo e, agora, com a garantia do contraditório. Para a determinação do valor das provas quase sempre utilizam apenas o depoimento 
dos próprios policiais militares envolvidos na prisão. Diferentemente de quaisquer outras testemunhas, sobretudo as da defesa, a credibilidade do testemunho policial é dada também pela aceitação da sua qualidade de perito no combate ao tráfico de drogas. Por óbvio, o "saber" policial é o recurso mobilizado. Os juízes, em sua maioria, partilham do repertório de crenças e, por isso, costumam apoiar-se na presunção de veracidade dos fatos conforme narrados pelos policiais e reforçados pelos promotores para sustentar suas decisões condenatórias.

Diante do repertório de crenças, o trabalho da defesa é difícil. As tentativas de garantir a absolvição por meio da denúncia de má conduta policial são as primeiras a serem notadas, contestadas e descartadas por juízes e promotores. Nesse ponto, o que o réu afirma diante do juiz é desacreditado como mentira. Sua fala válida é aquela narrada pelo policial, sobretudo quando se trata de uma "confissão informal". Resta, então, tentar obter a desclassificação da acusação de "tráfico" para "porte para uso". Para isso, revela a pesquisadora, os defensores lançam de argumentos cujo regime de verdade é o mesmo que os das narrativas policiais. Mais precisamente, mobilizam informações, por exemplo, sobre as condições pessoais e socioeconômicas dos réus, a quantidade e o tipo de droga apreendida com ele e o local da apreensão de forma a adequar os fatos ao que o "saber" policial considera constituir um caso típico de "porte para uso". A despeito de considerações sobre a eficiência dessa tática de defesa, importa que ela acaba por contribuir para o regime de validação das práticas inicialmente denunciadas (Jesus, 2018: 219).

Das entrevistas com os operadores do sistema, a pesquisadora obtém a informação de que, na verdade, eles conhecem, embora não reconheçam formalmente, os desvios policiais. Juízes e promotores deixam de exercer seus mandatos para o controle da legalidade da atividade policial; suas narrativas pertencem a uma espécie de campo de imunidade. Também é parte de suas atribuições a verificação do lastro no mundo empírico das narrativas que lhes são oferecidas, porém, também não atuam desse modo. Por qual razão? Ou, melhor, por qual razão esses espaços são preenchidos e, assim, precluídos de eficácia por um sistema de crenças? Isso porque, argumenta a pesquisadora, é por meio da realização do intento punitivo que o sistema de justiça criminal mede a própria eficácia. Isto é, a prisão de "traficantes" denota seu bom funcionamento e, em última instância, autoriza a reprodução de suas formas. Dispensada a crença, certamente um número muito menor de prisões seria computado; a impunidade aumentaria e o sistema seria afetado - embora o que se entende por impunidade ali ignora, em primeiro lugar, a própria 
justeza da punição. Em síntese, trata-se de uma resposta a uma necessidade que o sistema impôs a si próprio e que, então, passou a definir de que modo ele deveria funcionar (Jesus, 2018: 203).

Ao final, a análise se traduz na crítica ao encarceramento em massa, processo fundamentalmente relacionado às prisões relacionadas ao tráfico de drogas. Contudo, para que fosse possível enfrentar esse problema, restaria ainda identificar e analisar os mecanismos que definiram, em primeiro lugar, o sentido desse modo de operação do sistema de justiça criminal. Em outros termos, os pressupostos do sistema devem ser questionados de modo que seja possível colocar em movimento um processo de transformação de suas práticas em cujo centro está uma justiça criminal mais democrática e igualitária e menos encarceradora. Da mesma forma, a modificação da política de combate ao tráfico de drogas depende também da desnaturalização e crítica de suas premissas e dos estigmas que elas produzem. Se o texto não avança nesses pontos, todavia faz bem o trabalho de indicá-los aos demais pesquisadores do campo.

\section{Referências}

FOUCAULT, Michel. A verdade e as formas jurídicas. Rio de Janeiro, NAU Editora, 2005 (160).

JESUS, Maria Gorete Marques de. A verdade jurídica nos processos de tráfico de drogas. 1. ed. Belo Horizonte, Editora D’Plácido, 2018 (294).

LIMA, Roberto Kant de. Cultura jurídica e práticas policiais: a tradição inquisitorial. Revista Brasileira de Ciências Sociais, v. 4, n. 10, 1989, pp. 65-84.

. A polícia da cidade do Rio de Janeiro: seus dilemas e paradoxos. Rio de Janeiro, Polícia Militar do Estado do Rio de Janeiro, 1994 (266).

MILLS, Charles Wright. Situated actions and vocabularies of motives. American Sociological Review, Chicago, v. 5, n. 6, 1940, pp. 904-913.

MISSE, Michel. Crime, sujeito e sujeição criminal: aspectos de uma contribuição analítica sobre a categoria "bandido". Lua Nova: Revista de Cultura e Política, n. 79, pp. 15-38, 2010.

MUNIZ, Jacqueline de Oliveira. Fim da inocência: um ensaio sobre os atributos do saber policial de rua. In: SOUZA, Luís Antônio Francisco De; MAGALHÃES, Boris Ribeiro De; SABATINE, Thiago Teixeira (Eds.). Desafios à segurança pública: controle social, democracia e gênero. São Paulo, Cultura Acadêmica, 2012, pp. 13-41.

RUI, Taniele. Corpos abjetos: etnografia em cenários de uso e comércio de crack. Tese (doutorado em antropologia) - Instituto de Filosofia e Ciências Humanas, Universidade Estadual de Campinas, 2012. 
TEIXEIRA, Alessandra. Construir a delinquência, articular a criminalidade: um estudo sobre a gestão dos ilegalismos na cidade de São Paulo. Tese (doutorado em sociologia) - Faculdade de Filosofia, Letras e Ciências Humanas, Universidade de São Paulo, São Paulo, 2012.

Recebido em: 05/11/2018

Aprovado em: 10/05/2019

\section{Como citar esta resenha:}

CASTELUCI, Eduardo. Narrativas policiais, crenças jurídicas e a construção da verdade sobre o crime de tráfico de drogas. Contemporânea - Revista de Sociologia da UFSCar, v. 9, n. 2, maio - agosto 2019, pp. 699-707. 